\title{
The Role of Women's Traditional Gender Beliefs in Depression, Intimate Partner Violence and Stress: Insights from a Spanish Abbreviated Multicultural Measure
}

\author{
Montse Rovira ( $\square$ trecseo@gmail.com ) \\ Universidad de Deusto https://orcid.org/0000-0002-6354-0640 \\ Leonor Lega \\ Saint Peter's University \\ Carlos Suso-Ribera \\ Jaume I University: Universitat Jaume I \\ Izaskun Orue \\ University of Deusto: Universidad de Deusto
}

\section{Research article}

Keywords: Traditional gender beliefs, Intimate partner violence, Perceive Stress, Depression, Rational emotive behavior therapy, MC-O’Kelly women's beliefs scale

Posted Date: May 11th, 2021

DOI: https://doi.org/10.21203/rs.3.rs-505115/v1

License: (c) (i) This work is licensed under a Creative Commons Attribution 4.0 International License. Read Full License

Version of Record: A version of this preprint was published at BMC Women's Health on January 22nd, 2022. See the published version at https://doi.org/10.1186/s12905-021-01572-2. 


\section{Abstract}

Background: Research on traditional gender beliefs has highlighted their psychological impact and social implications for women. The purpose of this study was two-fold: firstly, to explore the relationship between women's traditional gender beliefs, intimate partner violence, stress and depression, and secondly, to adapt and validate the Spanish version of the Multicultural O'Kelly Women's Beliefs Scale. Based on the Rational Emotive Behavior Therapy framework, traditional gender beliefs were expected to be associated with higher levels of intimate partner violence, stress and depression. We also expected to obtain a psychometrically-sound factor structure of the Multicultural O’Kelly Women's Beliefs Scale.

Methods: A sample of Spanish women ( $N=322)$ completed the Multicultural O'Kelly Women's Beliefs Scale, the Beck's Depression Inventory II, the Modified Conflict Tactics Scale, and the Stress Perceived Scale. To test the psychometric properties of the Multicultural O'Kelly women's beliefs scale we implemented exploratory and confirmatory factor analyses and an analysis of the area under the curve.

Results: Regarding the psychometric properties of the scale, statistical analysis revealed a one-factor dimensionality (Global traditionalism) and supported a reduction of items in the original instrument. The abbreviated version (eight items) obtained the best fit indices. Considering the association between traditional gender beliefs and psychological outcomes, we found that traditional gender beliefs were associated with increased severity of stress, depressive symptoms and reciprocal verbal aggression.

Conclusion: The Spanish adaptation of the Multicultural O'Kelly women's beliefs scale provided a very short, psychometrically robust and clinically relevant measure of traditional gender beliefs. In addition to the association between traditional gender beliefs and mental health outcomes, an important finding was the relationship between traditional gender beliefs and intimate partner violence. Our scale might be used in clinical settings by helping women to identify their traditional gender beliefs and replace them by healthy and goal-oriented beliefs, which would also contribute in achieving a more egalitarian society.

\section{Background}

Wolfe's pioneering work on women's gender beliefs under the Rational Emotive Behavior Therapy (REBT) framework provided a women-centered perspective of traditional gender roles in clinical settings (Wolfe, 1995). Based on Ellis's and Wolfe's research (1979), O'Kelly (2011) specified that, when these beliefs are transmitted from one generation to another, we can speak of traditional gender beliefs (TGBs). Gender roles would be the expression of TGBs found in rigid gender stereotypes. Wolfe et al. (1996) defined TGBs as the set of beliefs (gender stereotypes) transmitted through a cultural learning process by which men and women think, feel, act and relate in a certain way (gender roles). Therefore, TGBs involve the upholding, both individually and collectively, of specific biased expectations regarding the behavior, preferences, responsibilities, activities, appearance, sensitivities etc. of individuals, often leading to the discrimination of those who do not follow these widely accepted stereotypes (Yoder, 2013). A paradigmatic example of TGBs is the biased acceptance of characteristics considered inherent to women (e.g., nurturing and caring) and men (e.g., self-reliance and assertiveness) (Littlefield, 2003). Recent studies on biased beliefs highlight their considerable impacts on welfare (Bordalo et al., 2019) and their social implications (e.g., discrimination) for both women and minorities (Glover et al., 2017).

According to the Office of the High Commissioner for Human Rights (OHCHR, 2020), a gender stereotype "is a generalized view or preconception about attributes or characteristics that are or ought to be possessed by women and men or the roles that are or should be performed by men and women"." In this sense, womanliness and manliness refer 
to traits, physical attributes, and behaviors that are based on the acceptance of the appropriate roles socially attributed to women or men. This generalized view consists of a shared belief system within the heart of a culture whereby specific characteristics are ascribed to individuals based on their sex (Moya, 2003).

Regarding gender issues, research around the world coincides in considering TGBs as essential features in relation to a range of individual beliefs, attitudes and decisions associated with gender: gender and health behaviors (Belgrave et al., 2016), gender and political participation (Cassese \& Holman, 2016), gender and occupation (Donley \& Baird, 2017), gender and value beliefs (Gaspard et al., 2015), gender and intimate partner violence (IPV) (Campbell, 2002; Golden et al., 2013; Kennedy et al., 2018), gender and cognitive abilities (Halpern et al., 2011), gender and work-life preferences (Leslie, 2019), gender and sexual orientation (Mize \& Manago, 2018), and gender and feminist identity (Weis et al., 2018). Research has also shown the influence of TGBs on women's psychological health, including depression (Khalsa et al., 2011; Céspedes, 2015; Block, 2018) as well as stress and anxiety (Yildiz et al., 2018; Balkis \& Duru, 2019). In addition, TGBs have been associated with gender abuse (McDermott \& Lopez, 2013; Fattah \& Camellia, 2020). Therefore, the modification of TGBs might provide resilience resources to women and minorities (Husnu \& Mertan, 2017).

Extensive literature has documented that beliefs about ourselves and others form the bedrock of many psychological issues that could be effectively addressed through psychological intervention (Xu \& Liu, 2017). However, before TGBs can be effectively targeted, it is essential to have psychometrically appropriate instruments to measure them. A measure of TGBs that has received attention from the research is the O'Kelly Women's Beliefs Scale (OWBS; O'Kelly, 2011). It was created following Wolfe's extensive research with women who received psychotherapy as a result of their anxiety about sex-love relationships, feelings of being disempowered at work and home, and self-concerns. The OWBS included 23 irrational or maladaptive beliefs about women's traditional gender role proposed by Wolfe and Naimark (1991), which were related to three content areas: (i) love and sex relationships ("It would be unbearable if I did not have someone stronger than myself to rely on"); (ii) self-sacrifice and victimhood ("I am nothing without a child"); and (iii) work and career ("I'm hopeless if I don't help others at work to get on well together"). Moreover, these 23 items were formulated according to the four inferences or irrational cognitive processes proposed in Rational Emotive Behavior Therapy (Ellis, 1977): demandingness (inflexible thinking: "I must have a husband/male partner"); awfulizing (situation perceived as the worst case scenario: "It would be/is awful not to have a husband/male partner"); low frustration tolerance (situation perceived as unbearable: "It would be/is unbearable not to have a husband/male partner"); and negative self-rating (self-downing: "If I do not take total care of my children I am a worthless person"). As a result, ninety items were included in the OWBS (O'Kelly, 2011)

In an attempt to obtain a reduced multicultural version of the OWBS, the 30-item MC-OWBS was created and tested in different cultures (Lega et al., 2014; 2018). Both the MC-OWBS and the original OWBS supported the Ellisonian assumption that TGBs could be grouped in terms of the aforementioned three content areas or four cognitive processes. However, neither the three- nor the four-factor solutions obtained sufficient support in previously published literature (O'Kelly, 2011; Lega et al., 2018). This is problematic because the use of artificial scales might lead to misdirected interpretations of the participant's scores and affect treatment plans.

The aim fo the present study was two-fold. Firstly, we attempted to obtain a psychometrically sound factor solution of the MC-OWBS to be used in routine care for a cross-cultural detection of TGBs. Secondly, we investigated the hypothesis that there is an association between TGBs and depression, IPV, and perceived stress (sources of criterion validity). Based on previous research, we expected a three- and four-factor solution based on content areas and processes to be difficult to replicate. We also expected that, once a robust factor structure was obtained, TGBs would be associated with more severe depressive symptoms, anxiety, and IPV. We hope that obtaining a psychometrically

Page 3/18 
robust and valid measure of TGBs will help clinical practice and the prevention of mental distress and gender violence toward women.

\section{Methods}

Study design and participants

The sample comprised 322 adult Spanish women $(M=21.4, S D=4.8)$. They voluntarily agreed to participate in the study and completed a series of questionnaires; only fully completed questionnaires were used. Our sample size exceeded the generally accepted recommendation of five participants per parameter (Kline, 2010). Regarding family status, 114 participants (36.8\%) were living with their partner, and $196(63.2 \%)$ reported having other situations.

\section{Data collection}

Participants were recruited using the snowball tecnique among the relatives and acquaintances of university students. Self-report paper-and-pencil questionnaires were used to collect the data. Participants' consent was obtained by filling a data sheet containing personal information without any identification. This was done to maintain confidentiality and anonymity. The questionnaires took approximately 7-10 minutes to complete. Participants were informed by the researchers that they could leave the study at any moment. The current research complied with APA ethical standards for human research and was approved by the University of Deusto Ethics Committee.

Measures

\section{Traditional Gender Beliefs}

To determine the participants' adherence to traditional gender beliefs, we used the 30 irrational items from the multicultural version of the O'Kelly Women's Beliefs Scale (MC-OWBS; Lega et al., 2014; Lega et al., 2018). The MCOWBS is a Likert-type scale that indicates the degree of adherence to a series of TGBs ( $1=$ completely disagree, $2=$ disagree, $3=$ neither agree or disagree, $4=$ agree, and $5=$ completely agree). The Colombian, multicultural version of the OWBS (Lega et al., 2014; Lega et al., 2018) was adapted to the Spanish culture, rewording original local expressions. To ensure the comparability of measures, two bilingual REBT-certified supervisors checked whether the translated items matched the original. Gender discriminating terms were avoided. For example, "husband/male partner" was replaced by "partner."

\section{Perceived Stress}

Stress was measured using the Perceived Stress Scale (PSS) originally developed by Cohen et al. (1983). Its Spanish version was validated by Remor and Carrobles (2001). This 14-item scale explores the degree to which people perceive daily situations as stressful (psychological stress). It is currently one of the most widely used scales to measure perceived stress and has obtained excellent psychometric properties in non-clinical samples (Remor, 2006; Trujillo \& González-Cabrera, 2007). Participants have to report whether they can control some situations or whether they feel overwhelmed by them (Pedrero-Pérez et al., 2015). Response scales range from zero (never) to four (very often). The total score is obtained by reversing the scores of items 4, 5, 6, 7, 9, 10 and 13 and then summing all items. Higher scores indicate higher perceived stress levels. The reliability of the stress scale in the present study was excellent (Cronbach's alpha $=0.85$ ).

\section{Depressive symptoms}


To measure depression, we used the Spanish version of the Beck Depression Inventory-II (BDI-Il; Sanz et al., 2003). The scale is a 21-item multiple-choice questionnaire in which each question has four alternative answers (except items 16 and 18, which have 7 response options). The total score ranges from 0 to 63 . According to the original BDI-II manual (Beck et al., 1996), categorical depression levels are: minimal(0-13), mild (14-19), moderate (20-28), and severe (29-63). The internal consistency of the BDI-II in the current sample was excellent (Cronbach's alpha $=0.93$ ).

\section{Intimate partner violence}

To evaluate IPV, we used the modified version of the Conflict Tactics Scale (M-CTS; Neidig, 1986) derived from the Conflict Tactics Scale (CTS) created by Straus (1979). This scale measures whether a couple uses reasoning or aggression as tactics to resolve their conflicts. The M-CTS consists of 18 bidirectional items about the committed (18 items) or suffered aggressions (18 items) within the couple (Neidig, 1986; Straus, 2004). It was validated in Spain by Muñoz-Rivas et al. (2007), who identified four conflict resolution factors or tactics: (i) reasoning as a non-aggressive way of resolution (items 1,2, and 3); (ii) psychological or verbal aggression in the form of arguments, insults, or threats (items 4, 5, 6, 7 and 8); (iii) average physical aggression, which includes harm or minor injuries (items 9, 10, 11, $12,13,14$ and 15); and (iv) serious physical aggression, which involves severe injuries (items 16, 17 and 18). The Likert response format indicates the frequency with which the aggressions occur: 1 (never), 2 (rarely), 3 (sometimes), 4 (often) and 5 (very often). Research has indicated poor internal consistency of the reasoning scale both as perpetrator and victim $(a<0.32)$ and acceptable reliability estimates $(0.63 \leq a \leq 0.82)$ for the remaining scales (Muñoz-Rivas et al., 2007). In the present study, the reliability of the reasoning scale both as perpetrator and victim was also poor ( 0.28 $\leq a \leq 0.34)$. The remaining internal consistency estimates were adequate $(0.68 \leq a \leq 0.95)$. According to these internal consistency estimates obtained in the present and previous research, there is insufficient evidence to support the reasoning scale. Therefore, this scale was ignored in the analyses.

\section{Data analysis}

Several statistical procedures were implemented to obtain a robust factor structure, including exploratory and confirmatory factor analyses (EFA and CFA, respectively) and an analysis of the area under the curve (AUC). Moreover, following past research (Koczkodaj et al., 2017), only a reduced number of items would be discriminative of depression (AUC analysis), which would support a reduction of items in the scale. The factor structures of the reduced version and the original 30-item versions were compared in an exploratory manner.

Previous research has supported a three-dimensional distribution of items in the multicultural version of the OWBS based on content areas, namely love, work, and self (Lega et al., 2014). However, the psychometric properties of this three-factor structure have been questionable. In this study, three approaches were followed to obtain a robust factor structure for the OWBS: a confirmatory factor analysis (CFA), an exploratory factor analysis (EFA), and an item reduction procedure (AUC analysis and selection of discriminative items of depressive symptomatology).

The CFA was used to test the fit of the aforementioned three-dimensional structure based on areas. Because the OWBS has also been conceptualized to evaluate the four irrational processes of thinking proposed in REBT (i.e., demanding, awfulizing, frustration intolerance, and self-downing), a 4-factor solution based on these processes was also investigated in a CFA.

CFA is often preferred to an EFA because the latter is data-driven as opposed to theory-driven. Moreover, as indicated in past research, exploratory solutions often resulted in factor structures that are difficult to interpret due to crossloadings and are difficult to replicate (Rovira et al., 2020). However, EFA is useful when the structure of a scale is unclear. Because this is the case for the multicultural version of the OWBS, an EFA was conducted to explore whether factor solutions and item distributions other than the ones tested in the CFA could obtain a better fit. One- to five-factor 
solutions were investigated. Solutions with more factors, which are less parsimonious, would be tested only if an adequate fit was not obtained with 1-to-5 factor solutions.

Finally, a reduction in the number of items (AUC analysis) followed by an EFA of the reduced set of items was used to obtain a more reliable factor solution for the scale. This strategy has been shown to be useful when attempting to obtain robust versions of a questionnaire and has additional advantages such as reducing the time required to complete the questionnaire (Mezquita et al., 2018). To minimize predictability loss due to item elimination, an AUC analysis was carried out to select the items to be included in a shortened version of the MC-OWBS (Koczkodaj et al., 2017). Depressive symptomatology was the criterion used in the AUC analysis. The cut-off to determine the existence of clinically relevant depressive symptomatology was 14, in line with past research (Beck et al., 1996).

Following these analyses, we explored sources of criterion validity with the version of the scale that obtained the best fit. The criteria used in this analysis of sources of validity were depressive symptoms, perceived stress, and IPV.

The estimator used in the CFA and the EFA was the diagonally weighted least squares. This is one of the preferred options with ordinal observed variables ( $\mathrm{Li}, 2016)$. Model fit was evaluated with the Chi-square test, the Tucker-Lewis index $(\mathrm{TLI})$, the comparative fit index $(\mathrm{CFI})$, and the root mean square error of approximation (RMSEA). TLI and CFI estimates over 0.95 and RMSEA scores below 0.05 indicate an excellent fit of the model to the data (Hu \& Bentler, 1999).

The AUC and the descriptive analyses were computed using IBM SPSS Statistics, version 22.0 (IBM Corp., 2013). The CFA and the EFA were conducted with Mplus, version 6.12 (Muthén \& Muthén, 2011).

\section{Results}

Results of the CFA, EFA, and AUC

As seen in Table 1, the 3-factor CFA obtained poor fit indices, especially when observing the statistics comparing the proposed model against the null model (i.e., TLI and CFI). In the EFA, solutions with at least three factors yielded an excellent fit to the data. Item distribution of the 3- and 4-factor solutions are presented in Table 2. These models are preferred to the 5-factor solution for parsimony and because the OWBS was conceptualized to evaluate 3 content areas (i.e., love, self, and work) and 4 thinking processes (i.e., demanding, awfulizing, frustration intolerance, and selfdowning). 
Table 1

Results of the confirmatory and exploratory factor analyses of the multicultural version of the O'Kelly Women's Beliefs Scale

\begin{tabular}{|llllll|}
\hline Factors & Chi-square & $\mathbf{p}$ & TLI & CFI & RMSEA $(90 \%$ CI $)$ \\
\hline 3-CFA & 1123.09 & $<.001$ & 0.879 & 0.888 & $0.075(0.069,0.080)$ \\
\hline 4-CFA & 1109.39 & $<.001$ & 0.650 & 0.679 & $0.074(0.069,0.080)$ \\
\hline 1-EFA & 1247.30 & $<.001$ & 0.860 & 0.870 & $0.080(0.075,0.085)$ \\
\hline -EFA & 802.63 & $<.001$ & 0.924 & 0.934 & $0.059(0.054,0.065)$ \\
\hline 3-EFA & 616.43 & $<.001$ & 0.948 & 0.958 & $0.049(0.043,0.055)$ \\
\hline 4-EFA & 508.51 & $<.001$ & 0.961 & 0.971 & $0.043(0.035,0.049)$ \\
\hline 5-EFA & 443.81 & $<.001$ & 0.966 & 0.977 & $0.040(0.032,0.047)$ \\
\hline $\begin{array}{l}\text { CFA, Confirmatory factor analysis; EFA, Exploratory factor analysis; TLI, Tucker-Lewis index; CFI, Comparative fit } \\
\text { index; RMSEA, Root mean square error of approximation. }\end{array}$ & \\
\hline
\end{tabular}

Table 2 shows the results of the EFA (3- and 4-factor solutions) and the AUC. It also shows the distribution items according to the CFA ( 3 areas and 4 processes), which is used to compare the item distribution in the CFA and the EFA. Only factor loadings equal to or greater than 0.40 are reported, as recommended in previous research (Williams et al., 2010). 
Table 2

Expected item distribution in the CFA and results of the EFA and AUC.

\begin{tabular}{|c|c|c|c|c|c|c|c|c|c|c|c|c|}
\hline \multirow{3}{*}{ Item } & \multicolumn{2}{|c|}{ Expected CFA } & \multicolumn{7}{|c|}{ EFA } & \multicolumn{3}{|l|}{ AUC } \\
\hline & \multirow[t]{2}{*}{ Content } & \multirow[t]{2}{*}{ Process } & \multicolumn{3}{|c|}{ Content } & \multicolumn{4}{|c|}{ Process } & \multirow[t]{2}{*}{ AUC } & \multirow[t]{2}{*}{$\mathrm{p}$} & \multirow[t]{2}{*}{$95 \%$ IC } \\
\hline & & & $\mathrm{F} 1$ & F2 & F3 & $\mathrm{F} 1$ & $\mathrm{~F} 2$ & F3 & $\mathrm{F} 4$ & & & \\
\hline 1 & Love & LFT & .67 & & & .68 & & & & .53 & .371 & $.46, .61$ \\
\hline 2 & Love & LFT & .43 & & .44 & & & & & .55 & .151 & $.48, .63$ \\
\hline 3 & Work & Awful & & & & & & & & .53 & .394 & $.46, .61$ \\
\hline 4 & Self & Downing & & & .54 & & & .47 & & .53 & .487 & $.45, .60$ \\
\hline 5 & Self & Downing & .41 & & & .44 & & & & .57 & .067 & $.49, .65$ \\
\hline 6 & Self & LFT & & & .47 & & & & .60 & .51 & .846 & $.44, .58$ \\
\hline 7 & Love & Demand & .74 & & & .73 & & & & .55 & .163 & $.48, .63$ \\
\hline 8 & Work & Awful & & .66 & & & .66 & & & .51 & .887 & $.43, .58$ \\
\hline 9 & Love & Awful & & & .78 & & & .87 & & .61 & .005 & $.53, .68$ \\
\hline 10 & Self & Demand & & & .44 & & & & .55 & .50 & .894 & $.42, .57$ \\
\hline 11 & Love & LFT & & & .83 & & & .82 & & .57 & .087 & $.49, .64$ \\
\hline 12 & Work & Downing & & & & & & & & .61 & .004 & $.54, .68$ \\
\hline 13 & Self & Awful & & & & & & & & .56 & .087 & $.48, .63$ \\
\hline 14 & Love & LFT & & .50 & & & .45 & & & .58 & .033 & $.51, .65$ \\
\hline 15 & Self & Demand & & & .60 & & & .51 & & .58 & .034 & $.50, .66$ \\
\hline 16 & Love & Downing & & .54 & & & .49 & & & .59 & .015 & $.52, .67$ \\
\hline 17 & Self & Downing & & .50 & & & .46 & & & .63 & $<.001$ & $.56, .71$ \\
\hline 18 & Love & Awful & .43 & .51 & & .45 & .45 & & & .60 & .006 & $.53, .68$ \\
\hline 19 & Work & LFT & & .75 & & & .73 & & & .51 & .901 & $.43, .58$ \\
\hline 20 & Self & Downing & & .73 & & & .70 & & & .55 & .207 & $.47, .62$ \\
\hline 21 & Work & Awful & & .79 & & & .80 & & & .54 & .284 & $.47, .62$ \\
\hline 22 & Work & Downing & & .84 & & & .82 & & & .52 & .531 & $.45, .60$ \\
\hline 23 & Self & Downing & & & .42 & & & & .55 & .52 & .519 & $.45, .60$ \\
\hline 24 & Love & Demand & & & .87 & & & .80 & & .55 & .186 & $.48, .63$ \\
\hline 25 & Love & Demand & & & .53 & & & & & .60 & .009 & $.53, .67$ \\
\hline
\end{tabular}

Expected CFA, expected item distribution in the confirmatory factor analysis; EFA, Exploratory factor analysis; AUC, Area under the curve; LFT, Low frustration tolerance. 


\begin{tabular}{|c|c|c|c|c|c|c|c|c|}
\hline \multirow[b]{2}{*}{26} & \multicolumn{2}{|c|}{ Expected CFA } & \multicolumn{3}{|l|}{ EFA } & \multicolumn{3}{|l|}{ AUC } \\
\hline & Love & Downing & .65 & .61 & & .55 & .205 & $.47, .62$ \\
\hline 27 & Self & Downing & .61 & .60 & & .55 & .164 & $.48, .63$ \\
\hline 28 & Self & Downing & .54 & .55 & .44 & .54 & .329 & $.46, .61$ \\
\hline 29 & Work & Demand & .88 & .86 & & .53 & .432 & $.45, .61$ \\
\hline 30 & Work & LFT & .60 & .56 & & .57 & .067 & $.49, .64$ \\
\hline
\end{tabular}

As seen in Table 2, a number of issues emerged in the 3- and 4-factor solutions obtained in the EFA. For example, several items had cross-loadings (e.g., items 2 and 18 in the 3 -factor solution and items 18 and 28 in the 4 -factor solution). In addition, a number of items had insufficiently meaningful loadings on both solutions (e.g., items 3,12 , and 13). Finally, the distribution of items largely differed from the assumed distribution (see CFA columns for a comparison).

Regarding the AUC analysis, as shown in Table 2, the items that obtained significant AUC estimates were items 9 (It is/it would be awful not to have a partner), 12 (I'm hopeless if I don't help others at work to get on well together), 14 (It would be so uncomfortable if I challenged the decisions and advice of my partner that I could not stand it), 15 (I must have a child to be fulfilled), 16 (I am an unpleasant person if I challenge and do not accept the decisions and advice of my partner), 17 (If I put my desires or wishes first I am an unlikeable person), 18 (It would be awful if I did not satisfy the wishes of my partner) and 25 (I must have someone stronger on whom I can rely).

Due to the reduced number of items, an EFA with 1 and 2 factors was conducted with this 8-item version of the multicultural OWBS. Both solutions obtained excellent fit indices ( 1 factor: $\chi^{2}=38.86, p=.012, \mathrm{TLI}=0.984, \mathrm{CFI}=$ $0.986, \mathrm{RMSEA}=0.051,90 \%$ CI RMSEA $=0.024,0.077 ; 2$ factors: $\chi^{2}=12.29, p=.504, \mathrm{TLI}=1.000, \mathrm{CFI}=1.000, \mathrm{RMSEA}$ $=0.001,90 \% \mathrm{Cl}$ RMSEA $=0.001,0.053)$. For parsimony reasons, the 1 -factor solution was preferred. The internal fit of this 8-item reduced version of the multicultural OWBS was very good (Cronbach's $a=0.79$ ).

Considering the previous results, the reduced 8-item measure of the multicultural OWBS (MC-OWBS-RV) was preferred over the original 30-item version. Reasons for this choice included poor fit of the confirmatory analyses with the expected item distribution according to past research and REBT principles (Lega et al., 2014, 2018), as well as psychometric and conceptual issues with the exploratory solutions (e.g., items with cross-loadings or insignificant loadings and item distribution that is inconsistent with theoretical principles). This leads us to believe that respondents were not able to differentiate between the expected areas or processes when completing the questionnaire. By contrast, the 8-item version had excellent psychometric properties (model fit and reliability indices) and could be interpreted as representing a measure of general irrationality regarding traditional gender roles.

Sources of criterion validity of the MC-OWBS-RV

As a final step towards obtaining a psychometrically and conceptually robust version of the multicultural OWBS, we tested sources of criterion validity of this reduced 8-item measure of the MC-OWBS-RV. The obtained correlations are shown in Table 3. Maladaptive or irrational beliefs, as measured with the MC-OWBS-RV, were associated with greater severity of stress $(r=.28, p<.001$; small size), depressive symptoms $(r=.35, p<.001$; medium size), and more verbal aggression both as perpetrator $(r=.22, p<.001$; small size $)$ and as victim $(r=.19, p<.001$; small size). A milder but still 
significant association was found between irrational beliefs and average and serious physical aggression as perpetrator $(r=.14, p=.011$; small size), as well as between irrational beliefs and serious aggression as victim $(r=.12$, $p=.039 ;$ small size).

Table 3

Means, standard deviations, and Pearson correlations between study variables.

\begin{tabular}{|c|c|c|c|c|c|c|c|c|c|}
\hline & \multirow[t]{2}{*}{ Mean (SD) } & \multicolumn{8}{|c|}{ Bivariate associations } \\
\hline & & 2 & 3 & 4 & 5 & 6 & 7 & 8 & 9 \\
\hline 1.MC-OWBS-RV & $13.61(4.21)$ & $.28^{\star \star \star}$ & $.35^{\star \star \star}$ & $.22^{\star \star \star}$ & $.19 \star \star \star$ & $.14^{*}$ & .06 & $.14^{\star}$ & $.12^{\star}$ \\
\hline 2.Stress & $2.84(0.56)$ & & 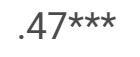 & $.31 * \star \star$ & $.20 * \star \star$ & .02 & -.02 & .03 & .05 \\
\hline 3.Depression & $11.45(3.56)$ & & & $.19 * \star \star$ & $.13^{\star}$ & .09 & .02 & $.12^{\star}$ & .11 \\
\hline 4.Verbal-me & 11.45 (3.56) & & & & $.84 * \star \star$ & $.31 * \star \star$ & $.29 * \star \star$ & .03 & $.13^{\star}$ \\
\hline 5.Verbal-other & 10.79 (3.36) & & & & & $.36 * \star \star$ & $.33^{\star \star \star}$ & $.11^{\star}$ & $.12^{\star}$ \\
\hline 6.Average-me & 7.52 (1.52) & & & & & & $.65^{\star \star \star}$ & $.65^{\star \star \star}$ & $.52^{\star \star \star}$ \\
\hline 7.Average-other & $7.51(1.78)$ & & & & & & & 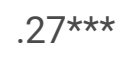 & $.58^{\star \star \star}$ \\
\hline 8.Severe-me & $3.03(0.46)$ & & & & & & & & $.68^{\star \star \star}$ \\
\hline 9.Severe-other & $3.02(0.17)$ & & & & & & & & \\
\hline
\end{tabular}

\section{Discussion}

The objectives of this study were two: (i) to obtain a transcultural useful instrument to measure TGBs with psychometric guarantees (good internal structure and adequate sources of criterion validity); and (ii) to investigated the hypothesis that TGBs are associated with stress, depression and the use of maladptive tactics to resolve conflicts (as a form of IPV). Using different methodological strategies, we obtained a reduced 8-item scale with very good psychometric properties, including criterion validity sources (depressive symptomatology, stress, and IPV). A onefactor solution, which was labeled as general irrationality, was parsimonious and had an excellent fit to the data.

Previous research on the original 90-item OWBS (O'Kelly, 2011) and the 30-item MC-OWBS (Lega et al., 2014, 2018) presented problems in their factor structure based on three areas (love, work, and self) or four cognitive processes (demanding, awfulizing, frustration intolerance, and self-downing). Two reasons may explain these results: (i) it is difficult for women to distinguish between areas and processes and/or (ii) irrationality is an overall trait that transcends areas and processes and constitutes a personality feature. While this is difficult to ascertain at this stage, the preference for a general traditional beliefs factor, as proposed in the present study, is consistent even though the scale was originally developed to reflect three content areas and four thought processes (O'Kelly, 2011). Following a series of analytical strategies, exploratory and confirmatory analyses did not support an item distribution based on these three or four dimensions. Therefore, we propose a one-factor solution of the MC-OWBS-RV (i.e., global traditionalism), which offers a parsimonious factor structure that is moderately associated with important outcomes, namely depressed mood, stress, and IPV, in the expected direction. 
Consistent with our proposed unidimensional structure of TGBs, the REBT's idea of irrationality was initially viewed as a global concept (Ellis, 1962). It was only some years later that this conceptualization evolved to differentiate specific irrational beliefs in diverse areas and according to distinctive cognitive processes. This was further developed by Ellis \& Wolfe $(1979)$ and extensively applied by Wolfe $(1985,1986)$ in allusion to women, covering conditions such as depression, relationship problems, work issues, sexual concerns, eating disorders, and gender abuse. Since Ellis and Wolfe's pioneering work, 48 inventories to assess rational and irrational beliefs have been developed, and many of them failed to report their factor analytic results according to the expected structures (David et al., 2019). These outcomes may be explained by the use of EFA as opposed to CFA. However, the authors still concluded that there is no evidence to support the theoretical idea that the best way to conceptualize irrational or rational beliefs is through dividing items by processes or areas (David et al., 2019). It has been suggested that perhaps all the processes, or a combination of some of them, represent a single latent variable (DiGiuseppe et al., 2020). Our results are in line with this alternative.

A strength of the present study is that the strategies used to obtain a psychometrically robust measure of TGBs were beyond the implementation of classic statistics (e.g., Cronbach's alpha). We conducted different statistical approaches to investigate the psychometric properties of the instrument, combining modern analytical methods (e.g., CFA and AUC). This allowed us to obtain a new reduced version of the scale that meets a varied number of psychometric requirements. Psychometrically, the MC-OWBS-RV is an 8-item unidimensional measure with statements revolving around roles, insights, musts, and gender stereotypes that women might self-impose. The scale also reflects women's insights into traditional cultural stereotypes involved in gender beliefs. These TGBs, as indicated in past research, diminish their roles as human beings, subordinating their values to what is socially accepted from a patriarchal society (O’Kelly \& Collard, 2016; O’Kelly \& Gilson, 2019).

Additional strengths of the MC-OWBS-RV include the fact that these beliefs are relevant cross-culturally (Lega \& Ellis, 2001; Lega et al., 2018) and that it has a reduced number of items (8) with a good predictive competence. In relation to the latter, there have been some calls for routine outcome monitoring of patients during therapy (Gual-Montolio et al., 2020), which should be performed more frequently (as opposed to the traditional episodic assessment in most randomized controlled trials). Having a reduced number of items, as in the MC-OWBS-RV, makes this more feasible. Ultimately, these eight gender beliefs may be used in goal-oriented clinical settings with the aim of alleviating symptomatology by helping women to become aware of and understand their thoughts and feelings, enhancing metacognitive capacities (Philipp et al., 2020).

Regarding the relation between beliefs and mental health, our results are in accordance with previous research on the maladaptive role of irrational beliefs in depression and stress (Balkis \& Duru, 2019). TGBs, as measured with the MCOWBS-RV, relate to greater severity of stress and depression, which is of critical significance in clinical interventions. Psychologists are committed daily to the real need to help men and women overcome their mental problems, improve their relationships and change attitudes that prevent them from living healthily.

In addition to the association between TGBs and mental health outcomes, an important finding was the association found between TGBs and IPV. These findings are consistent with previous research on the relevance of TGBs and their consequences in IPV (Thaller \& Cimino, 2017). Past research showed that IPV could be understood as a bidirectional phenomenon in which both parties use violence and/or abusive behaviors against one another (LanghinrichsenRohling et al., 2012; Sommer et al., 2017). This has significant implications for prevention purposes and underlines the critical importance of measuring TGBs. Because TGBs are relatively stable cognitive patterns, attitudes, and behaviors (Wolfe, 1992, 1995), research shows that TGBs act in different contexts and over time (Donley \& Baird; 2017). Therefore, addressing TGBs would be crucial in achieving a more egalitarian society.

Page $11 / 18$ 
Since REBT was created, six decades of subsequent research has fully evidenced the effectiveness of cognitive behavioral therapies (David et al., 1018). Thus, REBT and other forms of cognitive-behavioral interventions are now widely recognized as empirically-supported psychosocial treatments (David et al., 2019). As the cognitive approaches claim, core beliefs related to the self, the other, the world, or the future shape the way people think, feel and behave, by conditioning internal rules, attitudes, and assumptions derived from them (Joshi \& Phadke, 2018). Therefore, the early detection of maladaptive forms of thinking (e.g., TGBs) is extremely relevant in terms of prevention and treatment.

An important milestone in the field of public health is the elimination of gender violence. In this sense, the World Health Organization recommends cognitive behavior therapies as a way of alleviating the psychological consequences of the victims (WHO, 2013). Therefore, we emphasize the need to identify and challenge irrational cognitions that may have devastating costs and consequences on individuals, communities, and societies, particularly women who suffer gender violence (Campbell, 2002). According to this objective, Zapata-Calvente et al. (2019) highlighted that it is essential to change the beliefs promoted by gender socialization, "which foster male dominance and unequal relationships between men and women". Consequently, assessing TGBs is necessary to both advance in gender research and to construct a fairer society. Again, having a reduced set of core TGBs in the MCOWBS-RV might facilitate this task.

Beliefs have unique implications for understanding the impact of the experience of gender abuse (Ayala Albites, 2018). When women think irrationally, they hold dysfunctional, inaccurate, unhelpful, judgmental and/or unrealistic beliefs that constitute a vulnerability factor for managing potential stressors. Gender violence is indeed a major public health problem in Spain (MSSCl, 2020) and globally (WHO, 2013). Accordingly, the Spanish Government claimed in its Equality Delegation that there is fundamental work to be done toward changing our cultural model, attitudes, and values. To do so, traditional stereotypes need to be eliminated, and equality must be promoted. Similarly, freedom ought to be achieved, and all forms of violence against women need to be eradicated.

Unfortunately, many young women who suffered gender violence are unacknowledged victims who do not view their experience as a form of victimization (Littleton et al., 2017). Any phenomenon with a gendered view implies observing what is invisible (Salvai, 2013) and requires questioning mental patterns such as TGBs that may have been established and naturalized over centuries (Wolfe and Naimark, 1991).

Limitations

This study is limited due to the characteristics of the sample, which is restricted to mostly young women. However, this may be seen as an indicator of how education is changing - or not- the mindset of younger generations vis-à-vis traditional gender beliefs. Most of the participants were Caucasian and middle class, living in urban areas. Broader samples with women from different social and economic status, age, and geographic origins in the same country may reveal differences in the level of adherence to specific TGBs. The sexual orientation of the participants was unknown, which is another limitation of the study, and we cannot be certain whether the results indicate the presence of irrational thinking related to a specific sexual orientation. Even accounting for the limitations of the sample, it seems clear that there is a moderate association between TGBs, IPV, and their psychological consequences in terms of perceived stress and depression, which supports the utility of the proposed measure of TGBs.

\section{Conclusions}

To manage both psychological concerns and gender-based violence, it is particularly useful to have empirically supported tools to assess the degree to which TGBs may be acting as a conditioning unconscious mediating factor (e.g., helping to explain why some women remain under abusive situations, or why others do not disclose their 
personal history of gender violence or do not ask for help). The findings of this study contribute to a better understanding of the role that TGBs may have in women's life. Wolfe (personal communication, August 12, 2020) states that "the most important application of REBT to women's issues is identifying the should and must messages they get from their society starting with childhood; the goal is to feel better about oneself and the world, behaving in ways that lead to productive problem solving, improved communication and becoming more active in defining and achieving one's goals in life." Therefore, the present work represents an important step forward in this direction by providing a very short, psychometrically robust and clinically relevant measure of TGBs. Beliefs matter and can be changed. It is our hope that a cultural change regarding traditional gender beliefs may be promoted not only through policies but also through the daily work that psychologists carry out in therapeutic settings with the victims of cultural irrationalities. We hope that the existence of a short, 8-item measure of TGBs - designed from a multicultural perspective- that can be rapidly administered in routine care helps accomplish this goal.

\section{Abbreviations}

AUC (Analysis of the area under the curve), BDI-II (Beck Depression Inventory-II), CFA (Confirmatory factor analysis), CFI (Comparative fit index), CTC (Conflict Tactics Scale), EFA (Exploratory factor analysis), IPV (Intimate partner violence), LFT (Low frustration tolerance), MC-OWBS-RV (Reduced version of the Multicultural O'Kelly women's beliefs scale), M-CTS (Modified version of the Conflict tactics scale), MC-OWBS (Multicultural O'Kelly women's beliefs scale), MSSCI (Ministry of Health, Social Services and Equality), OHCHR (Office of the High Commissioner for Human Rights), OWBS (O'Kelly women's beliefs scale), REBT (Rational emotive behavior therapy), PSS (Perceived stress scale), TGB (Traditional gender beliefs), RMSEA (Root mean square error of approximation), TLI (Tucker-Lewis index), WHO (World Health Organization).

\section{Declarations}

Acknowledgements: Not aplicable

Authors contributions: MR designed the study, performed the sample, interpreted the results and was a major contributor in writing the manuscript. LL designed the study, created and revised the original scale and was involved in guiding all the work. CSR performed the analysis, interpreted the results and was a major contributor in writing the manuscript. 10 was involved in all the aspects of the study and was responsible for the fnal review of the manuscript. All the authors read and approved the final manuscript.

Funding: No funding was obtained for this study.

Ethics approval and consent to participate: The present study was approved by the Research Ethics Committee of the University of Deusto (Spain), reference number: ETK-21/18-19. Participants' consent was obtained verbally by filling a data sheet containing information without any personal identification to preserve confidentiality and anonymity.

Consent for publication: Not aplicable.

Competing interests: The authors declare that they have no competing interests.

\section{References}

1. Ayala Albites F. Efectividad de un programa de reeducación para mujeres, con antecedentes de denuncia por violencia de pareja, en la autoestima y la construcción de género. Investigación Valdizana. 2018;12(2):95-104.

Page $13 / 18$ 
https://doi.org/10.33554/riv.12.2.144.

2. Balkis M, Duru E. The Protective Role of Rational Beliefs on the Relationship Between Irrational Beliefs, Emotional States of Stress, Depression and Anxiety. Journal of Rational-Emotive Cognitive-Behavior Therapy. 2019;37(1):96-112.

3. Beck AT, Steer RA, Brown GK. BDI-II. Beck Depression Inventory-second edition manual. The Psychological Corporation; 1996.

4. Belgrave FZ, Abrams JA, Hood KB, Moore MP, Nguyen AB. Development and validation of a preliminary measure of African-American women's gender role beliefs. Journal of Black Psychology. 2016;42(4):320-42. https://doi.org/10.1177/0095798415576614.

5. Block J. (2018). Risk of Unintended Pregnancy in Latina Young Adults: The Effect of Gender Role Beliefs, Acculturation, and Depression. Dissertation, Psychology, Old Dominion University, https://doi.org/10.25777/q3vjrx19.

6. Bordalo P, Coffman K, Gennaioli N, Shleifer A. Beliefs about Gender. Am Econ Rev. 2019;109(3):739-73. https://pubs.aeaweb.org/doi/pdfplus/10.1257/aer.20170007.

7. Campbell J. Health consequences of intimate partner violence. Lancet. 2002;13:1331-6.

8. Cassese E, Holman M. Religious beliefs, gender consciousness, and women's political participation. Sex Roles. 2016;75(9-10):514-27. https://doi.org/10.1007/s11199-016-0635-9/.

9. Céspedes YM. Depression and suicidality in Latino adolescents: A study of acculturation and gender role beliefs. University of Southern California Digital Library (USC.DL); 2015.

10. Cohen S, Kamarck T, Mermelstein R. A global measure of perceived stress. J Health Soc Behav. 1983;24(4):38596.

11. David D, Cotet C, Matu S, Mogoase C, Stefan S. 50 years of rational-emotive and cognitive-behavioral therapy: A systematic review and meta-analysis. Journal of clinical psychology. 2018;74(3):304-18.

https://doi.org/10.1002/jclp.22514.

12. David D, Ştefan S, Terracciano A. Cognitive-Behavioral Therapy in the Cross-Cultural Context: An Extension of the Standard Paradigm from Individual to Country/Culture Level - A Brief Introduction into a New Research Line. Journal of Rational-Emotive Cognitive-Behavior Therapy. 2019;37:172-84. https://doi.org/10.1007/s10942018-0303-9.

13. DiGiuseppe R, Gorman B, Raptis J. The Factor Structure of the Attitudes and Beliefs Scale 2: Implications for Rational Emotive Behavior Therapy. Journal of Rational-emotive Cognitive-behavior Therapy. 2020;38(2):111-42.

14. Donley S, Baird C. The overtaking of undertaking? Gender beliefs in a feminizing occupation. Sex Roles. 2017;77(1-2):97-112. https://doi.org/10.1007/s11199-016-0699-6.

15. Ellis A. Reason and emotion in psychotherapy. L. Stuart; 1962.

16. Ellis A. Basic clinical theory of rational-emotive therapy. In: Ellis A, Grieger R, editors. Handbook of rationalemotive therapy. Springer; 1977. pp. 3-34.

17. Ellis A, Wolfe J. The intelligent woman's guide to dating and mating. Lyle Stuart; 1979.

18. Fattah KN, Camellia S. Gender Norms and Beliefs, and Men's Violence Against Women in Rural Bangladesh. Journal of Interpersonal Violence. 2020;35(3-4):771-93. https://doi.org/10.1177/0886260517690875.

19. Gaspard H, Dicke A, Flunger B, Schreier B, Häfner I, Trautwein U, Nagengast B. More value through greater differentiation: Gender differences in value beliefs about math. J Educ Psychol. 2015;107(3):663-77. https://doi.org/10.1037/edu0000003. 
20. Glover D, Pallais A, Pariente W. Discrimination as a Self-Fulfilling Prophecy: Evidence from French Grocery Stores. Q J Econ. 2017;132(3):1219-60.

21. Golden SD, Perreira KM, Durrance CP. Troubled times, troubled relationships: How economic resources, gender beliefs, and neighbourhood disadvantage influence intimate partner violence. Journal of Interpersonal Violence. 2013;28(10):2134-55. https://doi.org/10.1177/0886260512471083.

22. Gual-Montolio P, Martínez-Borba V, Bretón-López JM, Osma J, Suso-Ribera C. How Are Information and Communication Technologies Supporting Routine Outcome Monitoring and Measurement-Based Care in Psychotherapy? A Systematic Review. Int J Environ Res Public Health. 2020;17(9):3170.

https://doi.org/10.3390/ijerph17093170.

23. Halpern D, Straight C, Stephenson C. Beliefs about cognitive gender differences: Accurate for direction, underestimated for size. Sex Roles. 2011;64(5-6):336-47. https://doi.org/10.1007/s11199-010-9891-2.

24. Hu L, Bentler PM. Cutoff criteria for fit indexes in covariance structure analysis: Conventional criteria versus new alternatives. Structural Equation Modeling: A Multidisciplinary Journal. 1999;6(1):1-55.

https://doi.org/10.1080/10705 519909540118.

25. Husnu S, Mertan B. The Roles of Traditional Gender Myths and Beliefs About Beating on Self-Reported Partner Violence. Journal of Interpersonal Violence. 2017;32(24):3735-52.

26. IBM Corp. IBM SPSS statistics for windows, version 22.0. IBM Corp; 2013.

27. Joshi A, Phadke KM. Rational Emotive Behavior Therapy Integrated. Sage Publications; 2018.

28. Kennedy AC, Bybee D, McCauley HL, Prock KA. Young Women's Intimate Partner Violence Victimization Patterns Across Multiple Relationships. Psychology of Women Quarterly. 2018;42(4):430-44. https://doi.org/10.1177/0361684318795880.

29. Khalsa S, Mccarthy K, Sharpless B, Barrett M, Barber J. Beliefs about the causes of depression and treatment preferences. J Clin Psychol. 2011;67(6):539. https://doi.org/10.1002/jclp.20785.

30. Kline R. Principles and practice of structural equation modeling. 3rd ed.: Guilford Press; 2010.

31. Koczkodaj WW, Kakiashvili T, Szymańska A, Montero-Marin J, Araya R, Garcia-Campayo J, Rutkowski K, Strzałka D. How to reduce the number of rating scale items without predictability loss? Scientometrics. 2017;111:581-93. doi:10.1007/s11192-017-2283-4.

32. Langhinrichsen-Rohling J, Misra TA, Selwyn C, Rohling ML. Rates of bidirectional versus unidirectional intimate partner violence across samples, sexual orientations, and race/ethnicities: A comprehensive review. Partner Abuse. 2012;3(2):199-230. https:// doi.org/10.1891/1946-6560.3.2.199.

33. Lega L, Ellis A. Rational Emotive Behavior Therapy (REBT) in the New Millenium: A cross-cultural approach. Journal of Rational-Emotive Cognitive-Behavior Therapy. 2001;19(4):201-22.

https://doi.org/10.1023/A:1012537814117.

34. Lega L, Contreras AH, O’Kelly M, Kumar S, Alcid L, Rodríguez K. Multi-cultural Adaptation of the O’ Kelly Women Beliefs Scale to Samples in the US, India, Colombia, and Mexico. Business Perspectives Research. 2014;2(2):1-8. https://doi.org/10.1177/2278533720140201.

35. Lega L, Wisneski D, Contreras A, O'Kelly M, Kumar S, Lindenbaum A, Basaldua D. Women's irrational beliefs about traditional feminine sex role stereotypes with the multi-cultural version of the O' Kelly women beliefs scale. Psicología Conductual. 2018;26(3):407-20.

36. Leslie LM. Work-life ideologies: The contextual basis and consequences of beliefs about work and life. Acad Manag Rev. 2019;44(1):72-99. https://doi.org/10.5465/amr.2016.0410. 
37. Li C. (2016). Confirmatory factor analysis with ordinal data: Comparing robust maximum likelihood and diagonally weighted least squares. Behav Res Methods, 48(3), 936-49. https://doi.org/10.3758/s1342 8-0150619-7.

38. Littlefield MB. Gender role identity and stress in African American women. Journal of Human Behavior in the Social Environment. 2003;8:93-104. https://doi.org/10.1300/J137v08n04_06.

39. Littleton H, Grills A, Layh M, Rudolph K. Unacknowledged Rape and Re-Victimization Risk: Examination of Potential Mediators. Psychology of Women Quarterly. 2017;41(4):437-50. https://doi.org/10.1177/0361684317720187.

40. McDermott RC, Lopez FG. College men's intimate partner violence attitudes: contributions of adult attachment and gender role stress. Journal of Counseling Psychology. 2013;60(1):127-36.

41. Mezquita L, Camacho L, Suso-Ribera C, Ortet GG, Ibáñez MI, Ibanez MI. Development and validation of the alcohol Expectancy Questionnaire Short Form (EQ-SF). Adicciones. 2018;30:920. doi:10.20882/adicciones.920.

42. de Sanidad M. Servicios Sociales e Igualdad. MSSCI. (2020). National Strategy for the Eradication of Violence Against Women (2013-2016). MSSCI Centro de Publicaciones.

https://violenciagenero.igualdad.gob.es/planActuacion/estrategiaNacional/docs/Estrategia_Nacional_Ingles.pdf.

43. Mize TD, Manago B. Precarious sexuality: How men and women are differentially categorized for similar sexual behavior. Am Sociol Rev. 2018;83(2):305-30. https://doi.org/10.1177/0003122418759544.

44. Moya M. (2003). El análisis psicosocial del género. En J. F. Morales y C. Huici, editors. Estudios de psicología social, 175-221. UNED.

45. Muñoz-Rivas MJ, Andreu JM, Graña JL, O’Leary DK, González MP. (2007). Validación de la versión modificada de la Conflicts Tactics Scale (M-CTS) en población juvenil española. Psicothema, 19, (4), 693-698.

46. Muthén LK, Muthén BO. (2011). MPlus for windows, version 6.12. Muthén \& Muthén.

47. Neidig PM. The Modified Conflict Tactics Scale. Behavioral Sciences Associates; 1986.

48. O'Kelly M. Psychometric Properties of the O'Kelly Women's Belief Scales. Journal of Rational - Emotive Cognitive Behavior Therapy. 2011;29(3):145-57. https://doi.org/10.1007/s10942-010-0120-2.

49. O’Kelly ME, Collard JJ. Rational emotive behavior therapy. In: Nezu CM, Nezu AM, editors. The Oxford handbook of cognitive and behavioral therapies. Oxford University Press; 2016. pp. 142-59.

50. O'Kelly M, Gilson K. REBT with Women. In: Dryden W, Bernard M, editors. REBT with Diverse Client Problems and Populations. Springer; 2019. https://doi.org/10.1007/978-3-030-02723-0_15.

51. Office of the High Commissioner for Human Rights (OHCHR). (2020). Women's Human Rights and Gender Equality. Gender stereotyping. https://www.ohchr.org/EN/Issues/Women/WRGS/Pages/GenderStereotypes.aspx.

52. Pedrero-Pérez E, De León JM, Ruiz-Sánchez, Lozoya-Delgado P, Rojo-Mota G, Llanero-Luque M, Puerta-García C. La Escala de estrés percibido: estudio psicométrico sin restricciones en población no clínica y adictos a sustancias en tratamiento. Behavioral Psychology/Psicología Conductual. 2015;23(2):305.

53. Philipp R, Kriston, Kriston L, Kühne F, Härter M, Meister R. Concepts of Metacognition in the Treatment of Patients with Mental Disorders. Journal of Rational-emotive Cognitive-behavior Therapy. 2020;38(2):173-83.

54. Remor E. Psychometric properties of a European Spanish version of the perceived stress scale (PSS). Span J Psychol. 2006;9(1):86-93. doi:10.1017/S1138741600006004.

55. Remor E, Carrobles JA. Versión española de la escala de estrés percibido (PSS-14): Estudio psicométrico en una muestra VIH+. Ansiedad y Estrés. 2001;7(2-3):195-201.

56. Rovira M, Lega L, Suso-Ribera C, Orue I. Psychometric Properties of the Spanish Version of the O'Kelly Women's Beliefs Scale. Journal of Rational-Emotive Cognitive-Behavior Therapy. 2020. https://doi.org/10.1007/s10942- 
020-00356-1.

57. Sanz J, Perdigón LA, Vázquez C. Adaptación española del Inventario para la depresión de Beck-II (BDI-II): 2. Propiedades psicométricas en población general. Clínica y Salud. 2003;14:249-80.

58. Salvai ME. (2013). Treatment of scientific research on women studies, gender and feminism. Biblios, (50), 15-26. https://doi.org/10.5195/biblios.2013.81.

59. Sommer J, Babcock J, Sharp C. A Dyadic Analysis of Partner Violence and Adult Attachment. Journal of Family Violence. 2017;32(3):279-90.

60. Straus MA. Measuring intrafamily conflict and violence: The conflict tactics (CT) scales. Journal of Marriage Family. 1979;41(1):75-88. doi:10.2307/351733.

61. Straus MA. Cross-cultural reliability and validity of the Revised Conflict Tactics Scales: A study of university student dating couples in 17 nations. The Journal of Comparative Social Science. 2004;38(4):407-32.

62. Thaller J, Cimino AN. The Girl Is Mine. Violence against Women. 2017;23(2):202-21.

63. Trujillo HM, González-Cabrera JM. Propiedades psicométricas de la versión española de la "Escala de estrés percibido" (EEP). Behavioral Psychology/Psicología Conductual. 2007;15:457-77.

64. Weis AS, Redford L, Zucker AN, Ratliff KA. Feminist Identity, Attitudes Toward Feminist Prototypes, and Willingness to Intervene in Everyday Sexist Events. Psychology of Women Quarterly. 2018;42(3):279-90. https://doi.org/10.1177/0361684318764694.

65. Williams B, Brown T, Onsman A. (2010). Exploratory factor analysis: A five-step guide for novices. Australasian Journal of Paramedicine, 8(3).

66. Wolfe JL. Women. In: Ellis A, Bernard ME, editors. Clinical applications of rational emotive therapy. Plenum Press; 1985. pp. 101-27.

67. Wolfe JL. RET and women's issues. In: Ellis A, Grieger RM, editors. Handbook of rational-emotive therapy, 2. Springer Publishing Company; 1986. pp. 397-421.

68. Wolfe JL. Working with gay women. In: Freeman A, Dattilio KM, editors. Comprehensive casebook of cognitive therapy. Plenum Press; 1992. pp. 257-65.

69. Wolfe JL. Rational-emotive behavior therapy women's groups: A twenty-year retrospective. Journal of RationalEmotive Cognitive Behavior Therapy. 1995;13:(153-70).

70. Wolfe J, Naimark H. (1991). Psychological messages and social context. In Plenum, editor, Using rational-emotive therapy effectively (pp. 265-301). M. E. Bernard, editor.

71. Wolfe J, Shaughnessy M, Nystul M. An Interview with Janet Wolfe. Individual Psychology. 1996;52(4):441-57.

72. World Health Organization. Responding to intimate partner violence and sexual violence against women: WHO clinical and policy guidelines. WHO; 2013.

73. Xu L, Liu H. Effects of Rational Emotive Behavior Therapy (REBT) Intervention Program on Mental Health in Female College Students. NeuroQuantology. 2017;15(4):156-61.

74. Yildiz MA, Baytemir K, Demirtas AS. Irrational beliefs and perceived stress in adolescents: the role of self-esteem. Journal of Educational Sciences Psychology. 2018;8(1):78-89.

75. Yoder J. Women and Gender. Making a Difference. Sloan Publishing; 2013.

76. Zapata-Calvente AL, Megias J, Moya M, Schoebi D. Gender-related ideological and structural macrosocial factors associated with intimate partner violence against European women. Psychology of Women Quarterly.

2019;43(3):317-34. https://doi.org/10.1177/0361684319839367

Page $17 / 18$ 


\section{Supplementary Files}

This is a list of supplementary files associated with this preprint. Click to download.

- AdditionalFile1.docx

- AdditionalFile2.docx 